\title{
ANALYSIS OF THE IMPACT OF CHANGES IN FLIGHT SPEED AND ALTITUDE ON EMISSION INDEXES OF POLLUTANTS IN JET ENGINE EXHAUSTS
}

\author{
Malgorzata Pawlak \\ Gdynia Maritime University, Faculty of Navigation, Department of Ship Operation \\ Jana Pawla II Av. 3, 81-345 Gdynia, Poland \\ tel.: +48585586182 \\ e-mail:m.pawlak@wn.umg.edu.pl
}

\author{
Michał Kuźniar \\ Rzeszow University of Technology, Faculty of Mechanical Engineering and Aeronautics \\ Department of Aircraft and Aircraft Engines \\ Powstańców Warszawy Av. 8, 35-959 Rzeszow, Poland \\ tel.: +48178651466 \\ e-mail:mkuzniar@prz.edu.pl
}

\begin{abstract}
In currently implemented international aviation strategies and programs, including those realised under the European Union policy, such as Clean Sky, SES, SESAR and, CORSIA, the environmental aspect is particularly prominent - reducing the emission of all gaseous pollutants, and from 2020 also particulate matter. Therefore, it is important to know how the change in flight parameters (altitude, speed) affects the emission of pollutants in jet engine exhausts. Such information will enable to adjust the flight altitude of the aircraft when ecological aspect is taken into consideration. In addition to the operating condition (altitude, flight speed, range of power or thrust), the amount and type of pollutants emitted depends on the type of aircraft, its aerodynamic characteristics, engine type and as well as on the type of fuel used.

The impact of changes in aircraft flight parameters (speed and altitude) on the performance of a bypass jet engine and the emission of pollutants in its exhausts is analysed in the paper. For this purpose, the speed-altitude characteristics of such an engine were determined. Next, the emission indexes (EI) for the LTO phase taken from the ICAO database were used to determine the emission indexes corresponding to given parameters of both the engine operation and the aircraft flight. For selected speeds and cruising altitudes, the value of thrust required for the flight of the aircraft was determined and to this value, the engine operation range was assigned as well the corresponding pollutant emission indexes. This allowed to calculate the mass of pollutants emitted per unit of time for given flight parameters. The results obtained are presented in the graphs and discussed.
\end{abstract}

Keywords: aircraft, exhausts emission, bypass engine, emission index

\section{Introduction}

The emphasis is currently being placed on reducing the negative impact of air transport on the natural environment. Especially in the last decade, there have appeared a lot of regulations and projects that aim at reduction of the exhaust and noise emissions generated by aircraft engines. Projects such as Clean Sky, SES, SESAR and CORSIA give direction to research work on phenomena related to these emissions.

The paper focuses on the determination of emission indexes (EI) of toxic compounds in the jet aircraft's exhausts. The obtained values of EI for cruising conditions were compared to the values of these indexes obtained for static conditions on the ground. Knowledge of these values is necessary to determine the emission of particular compounds to be generated in the cruise phase for a given flight altitude and speed. 


\section{The research object}

In order to carry out the analysis, the Gulfstream IV aircraft was selected as a research object. Aircraft equipped a business jet with two jet engines. The aircraft is built in a Caravelle configuration (engines located at the tail part of the hull). This aircraft is eagerly used as a disposable aircraft, for private communication or operating from airports designed for air traffic of low intensity. The photo of the aircraft is shown in Fig. 1 and its technical data in Tab. 1.

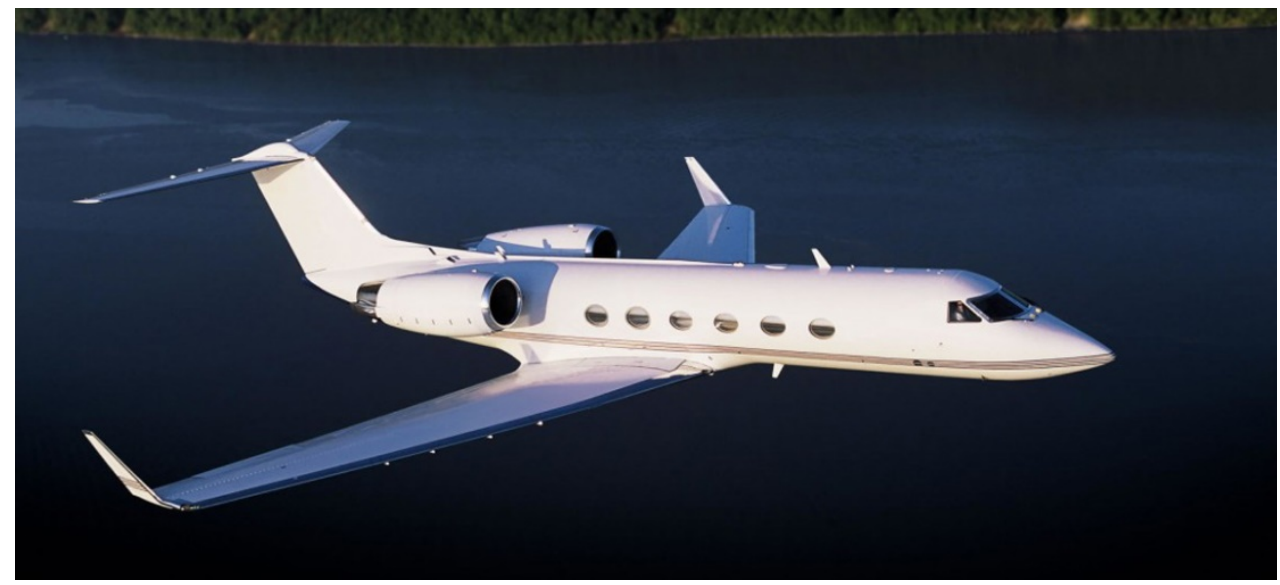

Fig. 1. Gulfstream IV[8]

Tab. 1. Technical data of the Gulfstream IV aircraft [7]

\begin{tabular}{|c|c|c|c|c|c|c|c|}
\hline $\begin{array}{c}\text { Seating } \\
\text { capacity }\end{array}$ & Length $[\mathrm{m}]$ & $\begin{array}{c}\text { Wingspan } \\
{[\mathrm{m}]}\end{array}$ & $\begin{array}{c}\text { Engines } \\
\text { type }\end{array}$ & $\begin{array}{c}\text { Static thrust } \\
{[\mathrm{N}]}\end{array}$ & $\begin{array}{c}\text { MTOW } \\
{[\mathrm{kg}]}\end{array}$ & Range $[\mathrm{km}]$ & $\begin{array}{c}\text { Maximum } \\
\text { speed }[\mathrm{km} / \mathrm{h}]\end{array}$ \\
\hline $14-19$ & 26.7 & 23.7 & $\begin{array}{c}2 \times \text { RR Tay } \\
\text { 611C }\end{array}$ & $2 \times 61600$ & 33200 & 7820 & 912 \\
\hline
\end{tabular}

\section{Determination of the impact of flight parameters on the pollutants emission}

Emission of harmful compounds depends mainly on the engine's operating parameters, i.e. its load resulting from the thrust required for flight of the aircraft for a string necessary for the flight through the aircraft. The changing environmental parameters (temperature and density) additionally affect the engine's gas-dynamic parameters. In order to determine these parameters, the methodology presented in previous publication by the authors [3-5] was applied. The computational procedure was based on the available source material [1].

In order to determine the value of thrust required for the flight, it is necessary to assume the aircraft mass, as well as to know the aerodynamic characteristics of the aircraft. The formula for the thrust required for the flight of the aircraft is as follows:

$$
P_{n}=\frac{1}{2} \rho \cdot V^{2} \cdot S \cdot C x,
$$

where:

$\rho$ - air density,

$P n$ - lift force,

$V$ - flight speed,

$S$ - wing area,

$C x$ - drag coefficient depended on the lift coefficient, and, as the consequence, on the aircraft weight [2].

The obtained course of the thrust required for the flight is shown in Fig. 2. 


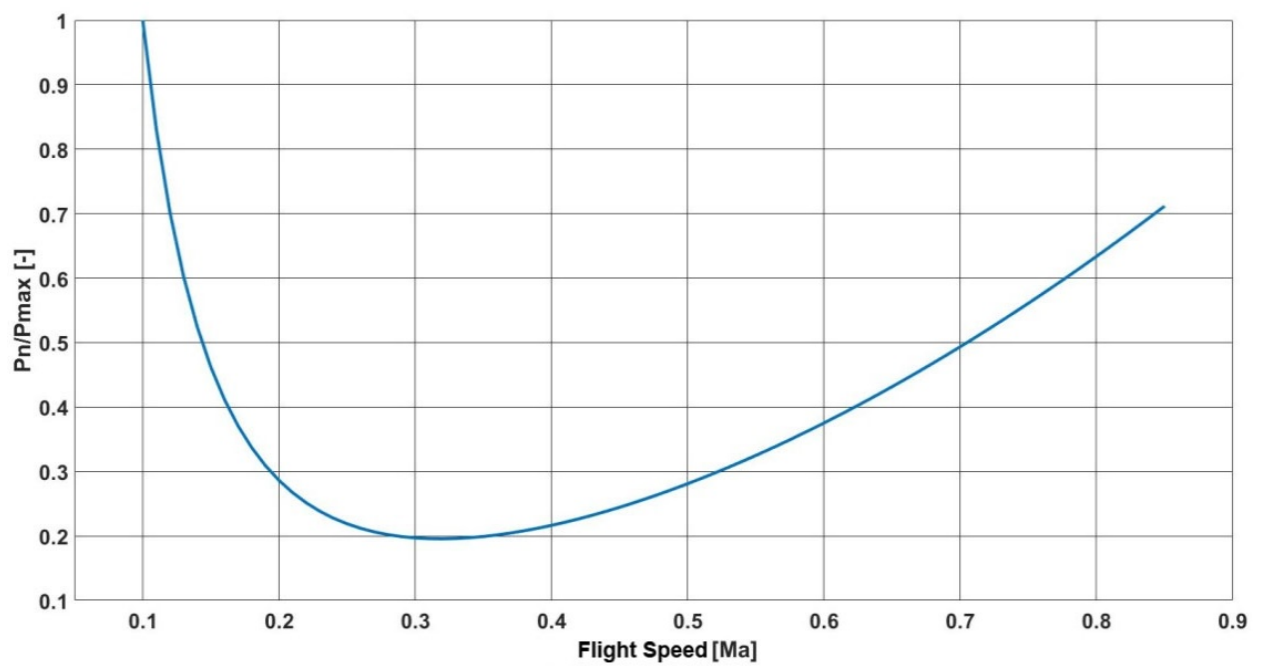

Fig. 2. Thrust required for the flight of Gulfstream IV

Knowing the value of thrust that required for the flight at a given altitude it is possible to select the engine's operating parameters. For the values of thrust and fuel consumption at sea level, using the reduction formulas $[3,5,6]$, it is possible to determine the engine performance depending on the altitude and speed of the flight. The dependence describing the change in air parameters can be given by:

$$
\begin{gathered}
T_{C}=T \cdot\left(1+0.2 \cdot M a^{2}\right), \\
p_{C}=p \cdot\left(1+0.2 \cdot M a^{2}\right)^{3.5},
\end{gathered}
$$

where:

$T c, p c$ - total temperature and pressure,

$T, p \quad$ - ambient temperature and pressure at given altitude (according to the International Standard Atmosphere, ISA),

$M a \quad$ - flight speed given in Mach.

On the basis of the computational methodology presented in the works [3, 4], the values of the engine thrust and SFC were determined for a given altitude as a function of the flight speed. Exemplary absolute parameters of the engine thrust are presented in Fig. 3.

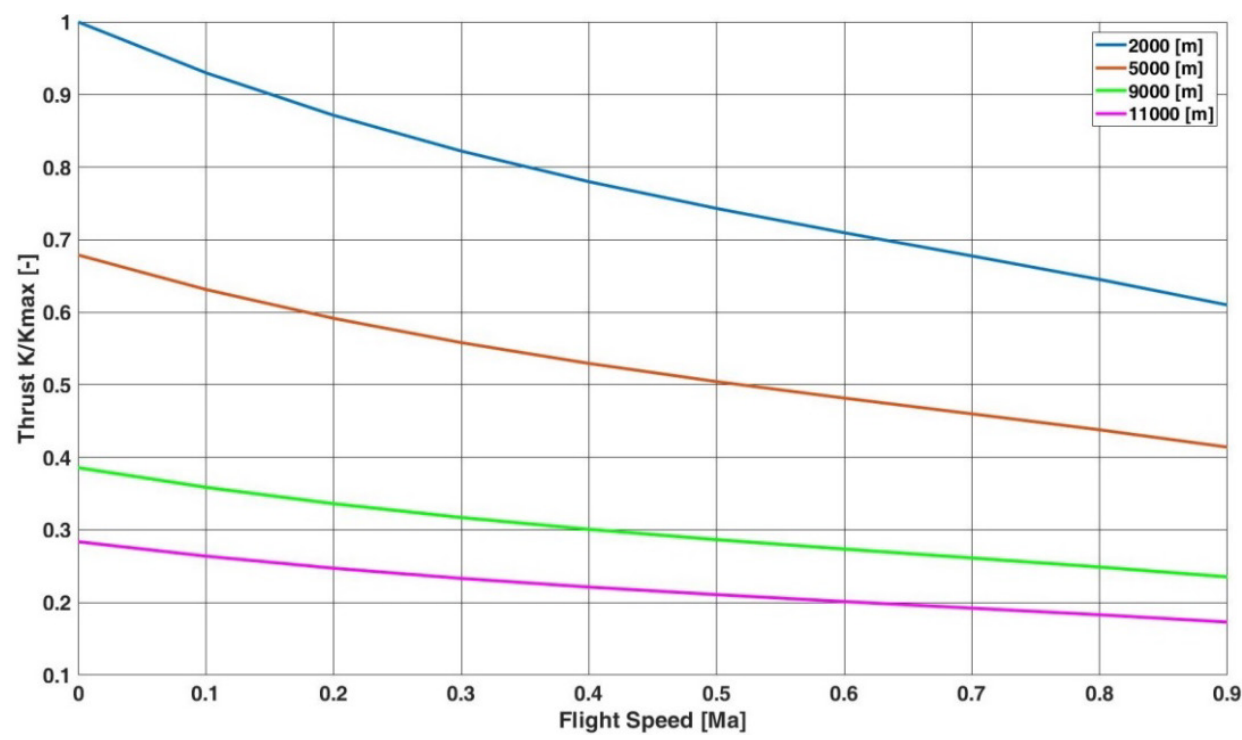

Fig. 3. Absolute thrust of the RR Tay 611C engine as a function of the flight altitude and speed (for different cruising altitudes) 
To determine the emission of toxic compounds in the exhausts of the jet engine, the emission indexes for Landing and Take-off Operations (LTO) were used. In order to relate the values of these indexes to the engine operation and flight parameters at a given altitude, the pressure, temperature, and humidity parameters for this altitude and flight speed should be taken into consideration. On this basis, the formulas for the reduction of emission indexes for individual pollutants can be derived [6]:

$$
\begin{gathered}
E I_{C O}=E I_{C O L T O} \cdot \frac{\theta^{3.3}}{\delta^{1.02}}, \\
E I_{H C}=E I_{H C L T O} \cdot \frac{\theta^{3.3}}{\delta^{1.02}}, \\
E I_{N O_{x}}=E I_{N O X L T O} \cdot \sqrt{\frac{\delta^{1.02}}{\theta^{3.3}}} \cdot e^{h},
\end{gathered}
$$

where:

$E I_{C O}, E I_{H C}, E I_{N O x}$ - emission indexes for $\mathrm{CO}, \mathrm{HC}$ and $\mathrm{NOx}$ at a given cruising altitude $[\mathrm{g} / \mathrm{kg}]$,

$E I_{C O L T O}, E I_{\text {HCLTO }} E I_{\text {NOxLTO }}$ - emission indexes for CO, HC and NOx measured for LTO parameters $[\mathrm{g} / \mathrm{kg}]$

$\theta$ - temperature change coefficient [-]:

$$
\theta=\frac{T_{C}}{288.15 K}
$$

where $\delta$ - pressure change coefficient [-]:

$$
\delta=\frac{p_{C}}{101325[P a]},
$$

where:

$e-$ Euler number $(\mathrm{e}=2.72)$,

$h$ - humidity correction factor, dependent on cruising altitude [-]:

$$
h=-19 \cdot(\omega-0.00634) \text {, }
$$

$\omega$ - specific humidity, where $\omega=10^{-3} \cdot e^{-0.0001426 \cdot(H-12900)}$ for ISA, where $\mathrm{H}-$ cruising altitude in units of feet.

Multiplying the emission index for a given pollutant ' $z$ ' being generated in a given time $t$ of the cruise phase by the $l$-engines of the aircraft moving with given thrust and specific fuel consumption, the amount of emitted pollutant in the mass unit [e.g. $\mathrm{kg}$ ], i.e. its emission, is obtained:

$$
E_{(z)}=E I_{(z)} \cdot K \cdot S F C \cdot t \cdot l,
$$

The most frequently used flight parameters were chosen for Gulfstream IV, i.e., the cruising altitude of $10 \mathrm{~km}$ and the flight speed of $0.8 \mathrm{Ma}$. Next, the EI indexes of $\mathrm{CH}, \mathrm{CO}$ and NOx were determined for them.

\section{Determination of the impact of flight parameters on pollutants emission}

Based on the presented methodology, the emission indexes for $\mathrm{HC}, \mathrm{CO}$ and $\mathrm{NOx}$ were determined. These indexes depended on both the engine's operating parameters and the ambient 
conditions. Fig. 4-6 present the obtained emission indexes (EI) as a function of speed and flight altitude as well as engine load.

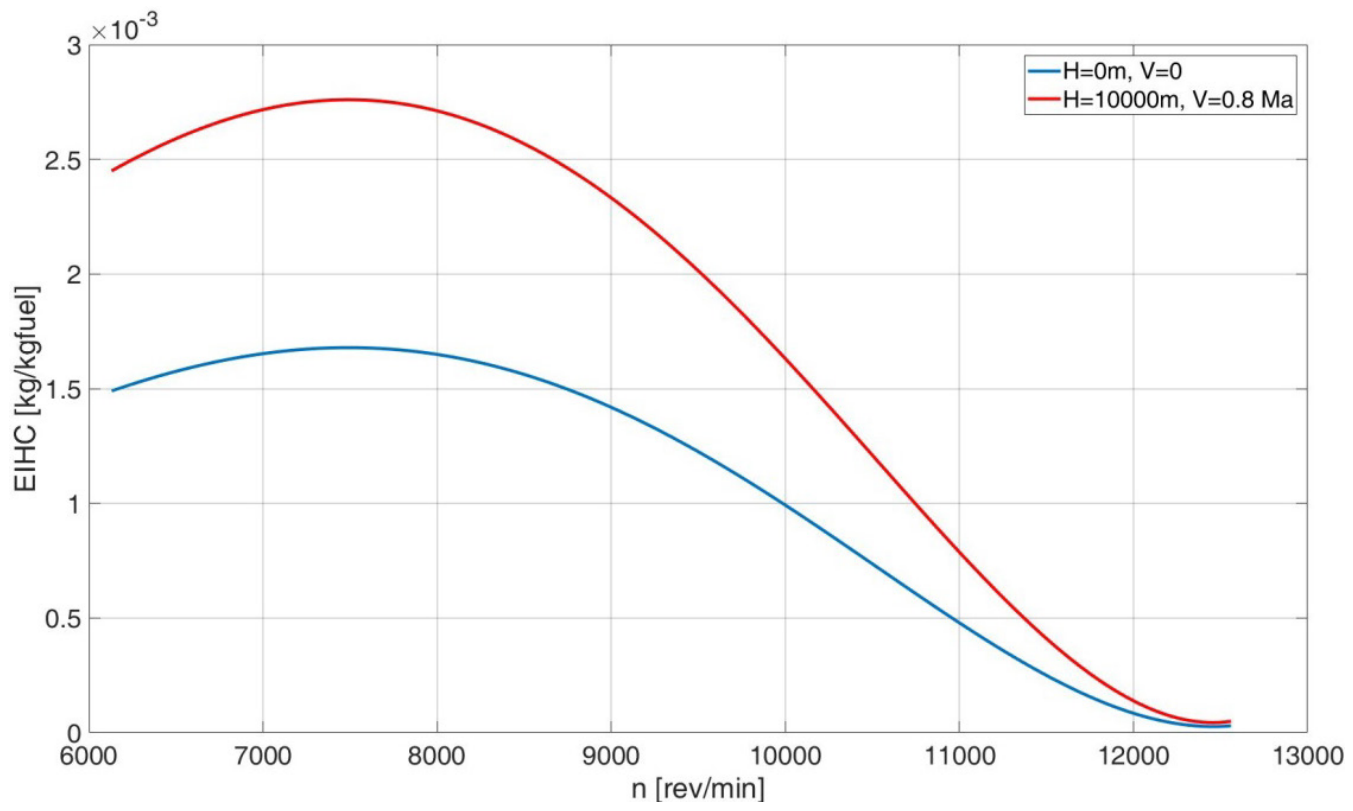

Fig. 4. Comparison of $E I_{H C}$ at ground level to $E I_{H C}$ at cruising altitude of $10000 \mathrm{~m}$

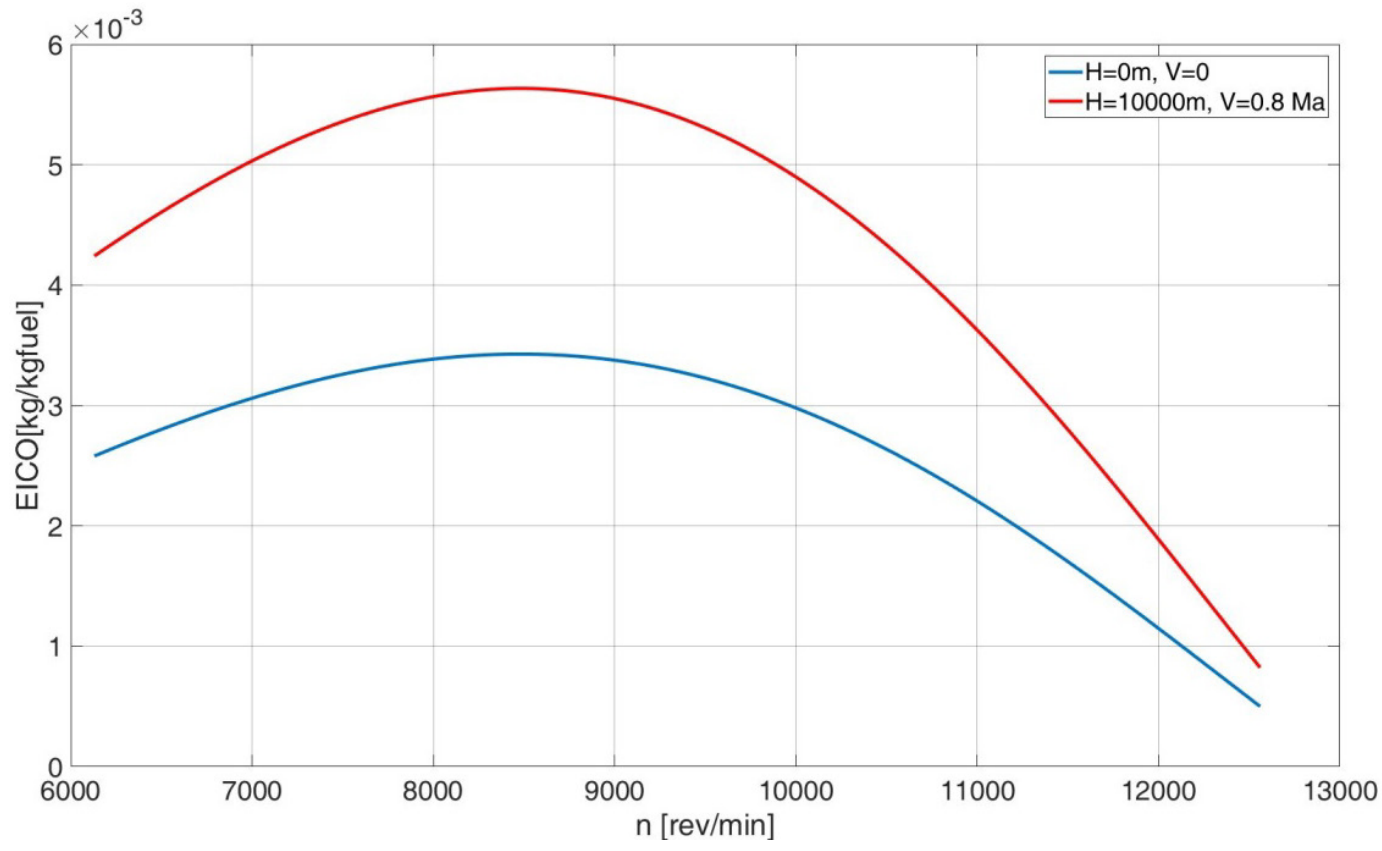

Fig. 5. Comparison of $E I_{C O}$ at ground level to $E I_{C O}$ at cruising altitude of $10000 \mathrm{~m}$

Changes in the ambient conditions and flight speed - from static on the ground level $(\mathrm{H}=0$ $\mathrm{km}, \mathrm{V}=0 \mathrm{Ma})$ to cruising conditions $(\mathrm{H}=10 \mathrm{~km}, \mathrm{~V}=0.8 \mathrm{Ma})$ - result in the increase of the values of EI indices for all pollutants considered, as follows:

- increase of $\mathrm{EI}_{\mathrm{HC}}$ from 0.25 to $0.5[\mathrm{~kg} / \mathrm{kg}$ of fuel burned], i.e. by $100 \%$,

- increase of EICO from 1.8 to 3.8 [kg/ $/ \mathrm{kg}$ of fuel burned], i.e. by $111 \%$,

- increase of $E I_{\text {NOx }}$ from 0.01 to 0.0295 [kg/ $/ \mathrm{kg}$ of fuel burned], i.e. by $195 \%$.

At high altitude and flight speed, the values of $\mathrm{HC}, \mathrm{CO}$ and $\mathrm{NO}_{\mathrm{x}}$ emission indexes increase, which is related to different combustion conditions (pressure, temperature and air humidity). It should be noted that the value of the thrust generated by the engine decreases along with the 
increase of the flight speed. Fig. 7 shows the performance characteristics of the RR Tay engine determined at the analysed cruising altitude of $0.8 \mathrm{Ma}$. The obtained performance was compared to static performance at ground level.

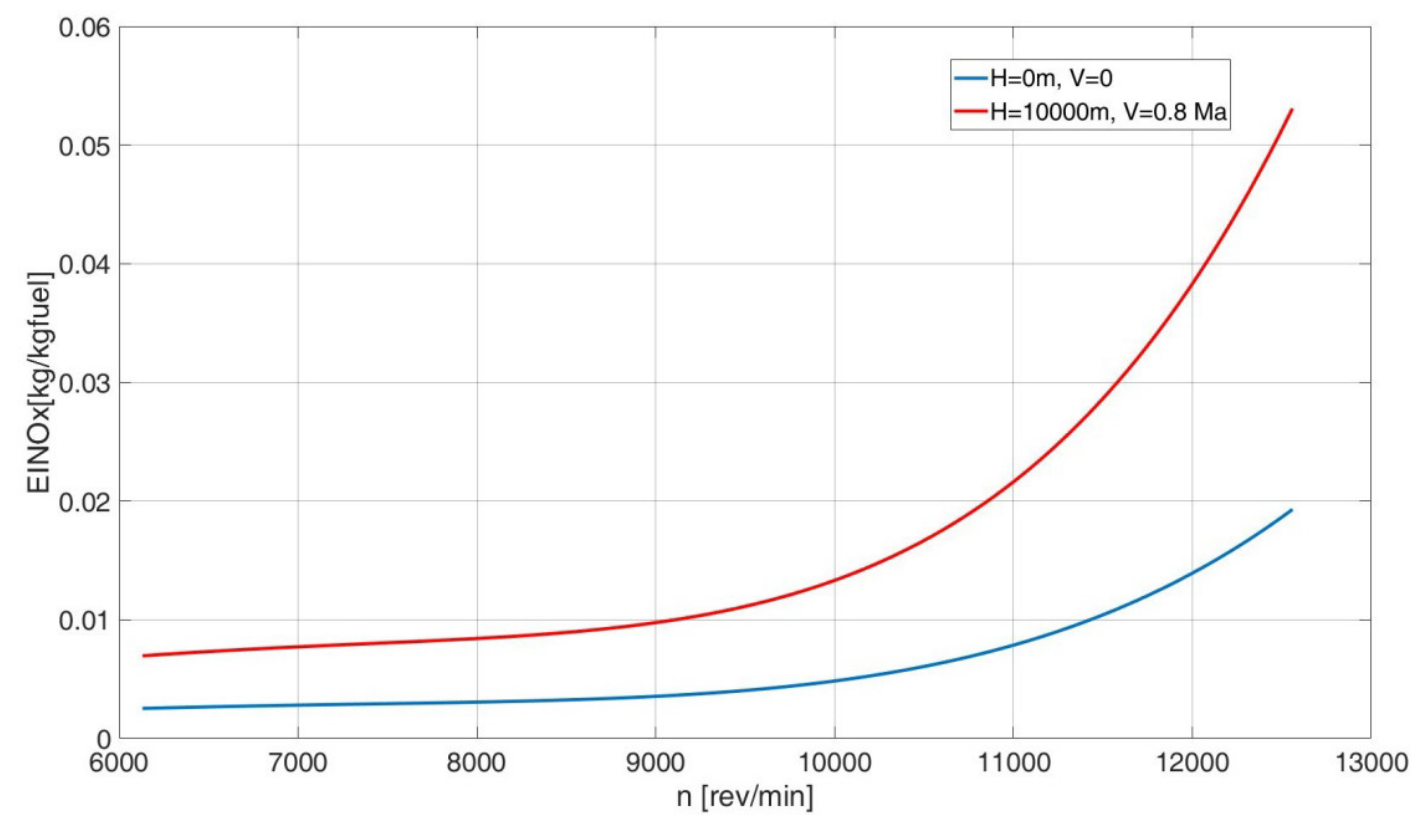

Fig. 6. Comparison of $E I_{N O x}$ at ground level to $E I_{N O x}$ at cruising altitude of $10000 \mathrm{~m}$

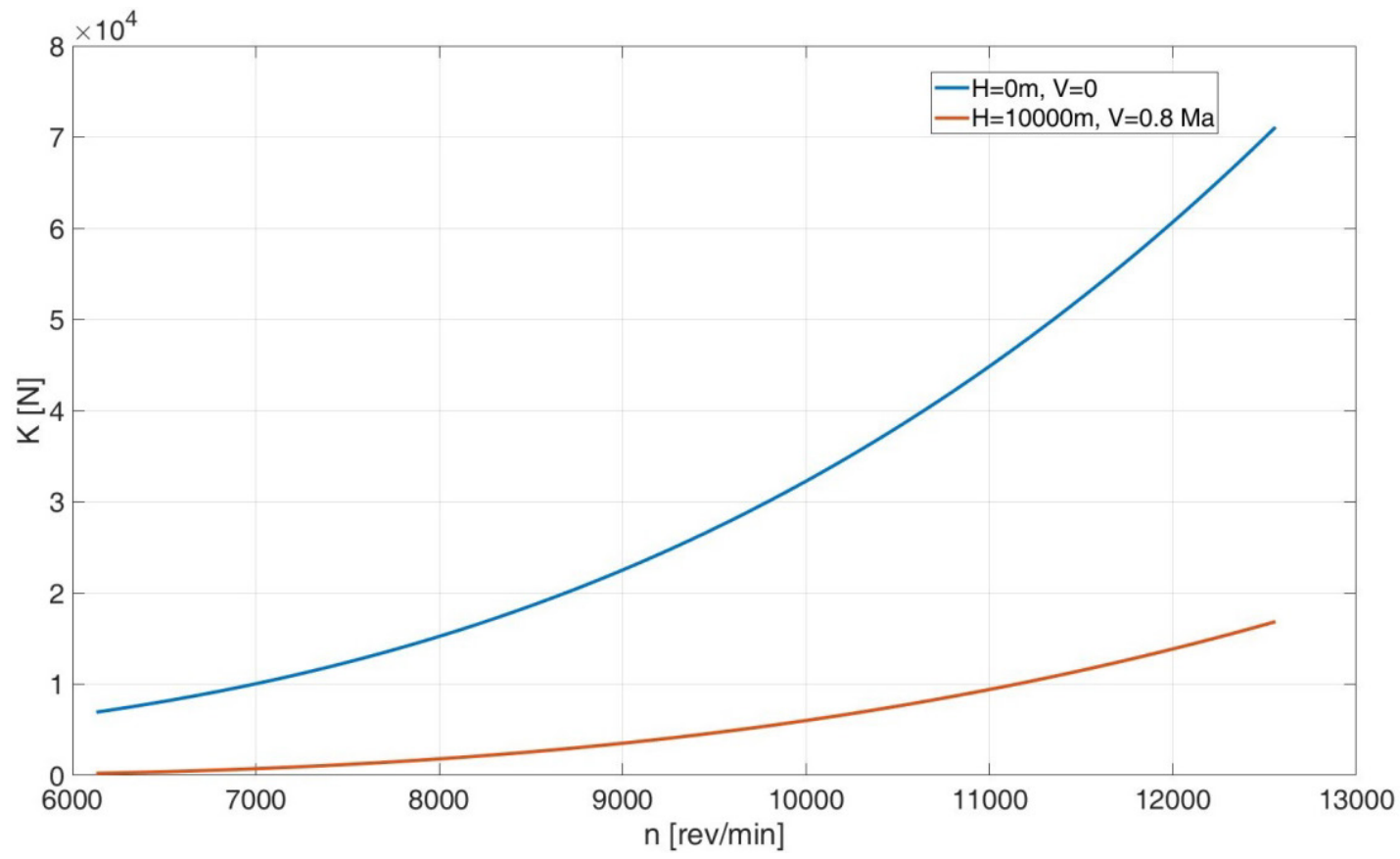

Fig. 7. Comparison of thrust at ground level as a function of engine speed to thrust at cruising altitude

As shown in Fig. 7, the engine thrust for the cruising and maximum range reaches the value even four times lower than the reference value - static conditions on the ground. To maintain the same value of thrust while lowering the flight altitude, it is necessary to increase the engine load, which will directly result in the increase of fuel consumption. Based on the analysis of the presented relationships, it can be concluded that the emission of pollutants in the exhausts depends on all of the above-mentioned parameters of the engines operation as well as the aircraft configuration. 


\section{Conclusions}

The analysis conducted allows drawing the following conclusions:

1. The values of emission indices depend significantly on the engine load and flight parameters (altitude and flight speed);

2. Increase in the emission indices is observed for the cruising conditions in relation to the static parameters on the ground.

Knowing the parameters of emission indices for the cruising range it is possible to determine the pollutants emission in the exhausts. It is necessary to know the time of flight at a given altitude and the number of engines installed in the aircraft.

\section{References}

[1] EASA, EEA, EUROCONTROL, European Aviation Environmental Report 2016, online: www.eurocontrol.int/sites/default/files/publication/files/european-aviation-environmentalreport-2016.pdf, 2016.

[2] Filippone, A., Advanced Aircraft Flight Performance, Cambridge University Press., 2015.

[3] Pawlak, M., Majka, A., Kuźniar, M., Pawluczy, J., Analysis of wind impact on emission of selected exhaust compounds in jet engines of a business jet aircraft in cruise phase, Combustion Engines, 173(2), pp. 55-60, 2018.

[4] Pawlak, M., Majka, A., Kuźniar, M., Pawluczy, J., Emission of selected exhaust compounds in jet engines of a jet aircraft in cruise phase, Combustion Engines. 173(2), pp. 67-72, 2018.

[5] Pawlak, M., Metoda modelowania emisji szkodliwych $i$ toksycznych składników spalin turbinowych silników odrzutowych samolotów pasażerskich $w$ warunkach przelotowych, Gdynia 2019.

[6] Schäfer, W. A., Waitz, A. I., Air transportation and environment, Transport Policy 34, 2014.

[7] www.gulfstream.com/.

[8] www.starjets.net/aircraft/gulfstream-iv/.

Manuscript received 04 March 2019; approved for printing 21 June 2019 